\title{
Analysis of in vitro activity of high dilutions of Euphorbia tirucalli $L$. in human melanoma cells
}

\author{
Renata Macedo dos Reis Januário da Silva1, Dulcinéia Furtado Teixeira ${ }^{1,3}$, \\ André Luiz Franco Sampaio ${ }^{3}$, Tereza Cristina de Aguiar Leitão ${ }^{1,2}$
}

(1) Estácio de Sá University, Rio de Janeiro, Brazil

(2) Fluminense Federal University, Rio de Janeiro, Brazil,

(3) Farmanguinhos-FIOCRUZ, Rio de Janeiro, Brazil.

\begin{abstract}
Aveloz (firestick cactus; Euphorbia tirucalli L.) belongs to Euphorbiaceae family, characterized by the production of a toxic latex that has corrosive effects on the skin and mucous membranes. Continual topic use of the latex is recommended by popular medicine to treat warts, and epitheliomas. To validate this indication, ultra diluted latex and homeopathic medicine Euphorbia tirucalli were tested in vitro on the proliferation of melanoma cells. Ultra diluted latex was prepared in homeopathic dilutions $5 \mathrm{cH}, 15 \mathrm{cH}$ and $30 \mathrm{cH}$ by dilution and agitation (trituration for solid and sucussion for liquid phases) using $70^{\circ} \mathrm{GL}$ (Gay Lussac) ethylic alcohol $\left(70^{\circ} \mathrm{GL}\right.$ EtOH $\left.70^{\circ} \mathrm{GL}\right)$ as inert medium according to the guidelines in Farmacopéia Homeopática Brasileira (FHB). Homeopathic medicine Euphorbia tirucalli was prepared from mother-tincture according to the centesimal Hahnemannian method. Solutions $0.5 \%$ and $5 \%$ of $70^{\circ} \mathrm{GL}$ EtOH were succussed and used as control. Human melanoma cells were cultured, treated and monitored by method MTT for 24 to 72 hours. It was observed that $0.5 \% 70^{\circ} \mathrm{GL} \mathrm{EtOH}$ solution had little or no effect on the proliferation of melanoma cells (5.1\% maximal inhibition in dilution $30 \mathrm{cH})$. Positive correlation was observed in most groups between inhibition of proliferation and diluted preparations, maximal increase (9\%) was seen in with 5\% latex. Moreover, mother-tincture proved to be more active than latex; treatment with $0.5 \%$ solution of latex $30 \mathrm{cH}$ exhibited $19.7 \%$ inhibition, whereas treatment with $0.5 \%$ solution of Euphorbia tirucalli $30 \mathrm{cH}$ exhibited $32.1 \%$ inhibition of cell proliferation $(\mathrm{p}<0.05)$. These results suggest that high dilutions of firestick cactus (especially dilution $30 \mathrm{cH}$ ) might have a therapeutic indication in melanoma, further studies are needed in this regard.
\end{abstract}

Keywords: Euphorbia tirucalli, High dilutions, Antitumor activity

\section{Introduction}

Aveloz (firestick cactus; Euphorbia tirucalli L.) is a plant belonging to family Euphorbiaceae, which is characterized by the production of a toxic latex that has corrosive action on the skin and mucous membranes [1]. This plant is native of Africa and was brought to Brazil in 1892; it is popularly known also as Indian tree spurge, naked lady, pencil tree, sticks on fire and milk bush [2]. As general characteristics, it is a milky, pubescent and subligneous shrub, with cylindrical, verticillated and filiform green-hued branches (figure 1); female flowers are terminal and axillary and have a yellowish or greenish hue, whereas male flowers surround them [3]. 


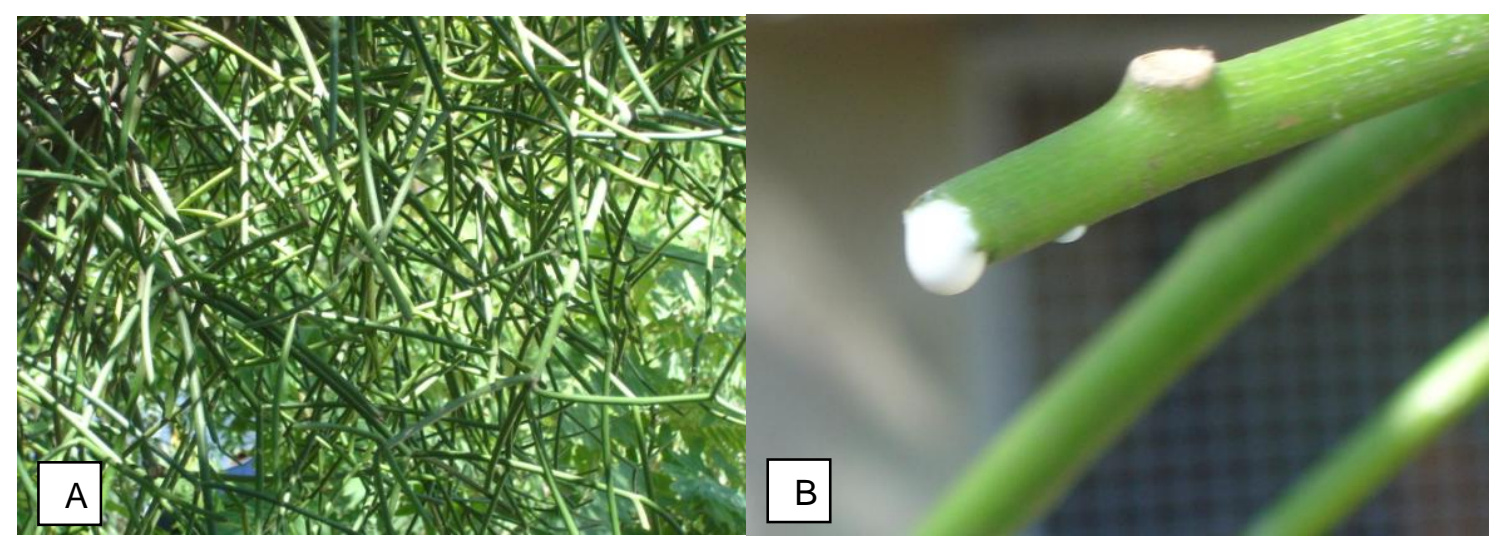

Figure 1: Euphorbia tirucalli L., A. the firestick cactus, aerial parts; B. detail of oozing latex.

The phytochemical composition of stalks include anthocyanins (condensed tannins), flavonoids and traces of alkaloids and steroids, whereas triterpenoids and diterpenoids are found in the latex [4;5]. Triterpens euphol, tirucallol, taraxasterol, several organic acids, hydrocarbons and an isoquinolinic derivate were isolated in African E. tirucalli; most of them are biologically inert, parental alcohols ingenol and phorbol are not tumorpromoters, different from the diterpenic esters of phorbol [5;6]. In popular medicine, internal use of the latex is indicated in warts and benign epitheliomas; it is also used against scorpion stings and snakes bites, as well as a purgative. External use has anti-rheumatic and rubefacient indications and it is also employed to treat warts [5,6]. Although this plant has been commonly used to build living fences, this use is not recommended due to the toxicity of the latex [5;6].

According to the Brazilian Cancer National Institute (INCA), malignant neoplasm are the second cause of mortality in Brazil since 2003 - these data were modified in 2007 [7]. This high prevalence stimulates cancer research, including the investigation of the ancient popular belief about the effectiveness of firestick latex in topical skin conditions [8].

A study by Silva [9] evaluated the acute toxicity of firestick and observed anti-inflammatory/analgesic and antitumor activity. In popular medicine and homeopathy, firestick cactus has been used as complementary treatment in cancer [10]. Caxito [11] observes that the chemical composition of E. tirucalli L. varies according to different environmental conditions. For this reason, to establish its actual cytotoxicity studies must take geographical and seasonal variations into account.

According to some sources of homeopathic materia medica, whereas high doses of firestick can cause toxic effects, diluted and agitated doses can be used therapeutically when there is terebrant pain or symptoms similar to neoplasm $[12,13,14]$.

It is held that homeopathic doses have an essentially qualitative rather than quantitative nature, this is, they differ from the large doses used in conventional medicine grounded on the assumption that the amount of medicine taken by a patient is able to alter his or her state of health [15].

Varricchio et al [16] report antitumor activity by firestick cactus in vivo and in vitro with the use of high dilutions $5 \mathrm{cH}, 15 \mathrm{cH}$ and $30 \mathrm{cH}$.

\section{Materials and Methods}

Latex of E. tirucalli L. was collected from a sample cultivated in the garden of Oswaldo Cruz Foundation, Rio de Janeiro. Collection was performed in the evening from stems directly taken from the plant. $0.1 \mathrm{~g}$ of latex was obtained and kept refrigerated for 24 hours, and then it was grinded in lactose up to dilution $3 \mathrm{cH}$ in a 
porcelain mortar according to the procedure described in Farmacopeia Homeopática Brasileira [17]. Next, dilution $3 \mathrm{cH}$ was dissolved in $20^{\circ} \mathrm{GL}$ EtOH and succussed to obtain dilution $4 \mathrm{cH}$. Dilution $5 \mathrm{cH}$ was prepared by mixing 1 part of dilution $4 \mathrm{cH}$ and 99 parts of $70^{\circ} \mathrm{GL}$ EtOH. This process diluting 1:100 followed by mechanic succussion (Denise 10-50 AUTIC) of each successive dilution was repeated until dilution 30cH. This procedure was used to prepare homeopathic medicine Euphorbia tirucalli, high diluted latex and high diluted EtOH.

\section{Test of activity on cell growth}

MV3 human melanoma cells (supplied by Prof Dr Thereza Christina Barja-Fidalgo, IBRAG, State University of Rio de Janeiro) were cultured in DMEM medium supplemented with $10 \%$ fetal bovine serum and antibiotics (streptomycin and penicillin). $100 \mu \mathrm{L}$ cells were sown in 96 plates (5.10 ${ }^{3}$ cells/well plate) and kept at $37^{\circ} \mathrm{C}$ in incubator with $5 \% \mathrm{CO}_{2}$ and $100 \%$ relative humidity.

After 24 hours, high dilutions were diluted $0.5 \%$ and $5 \%$. Serial dilutions were made (twice) to a total of 2 dilutions for each compound and ultra diluted vehicle (70\% EtOH). $100 \mu \mathrm{L}$ of test solutions were added to the plates containing $100 \mu \mathrm{L}$ of culture medium thus attaining the desired dilutions $(0.5 \%$ and $5 \%) 3$ times.

After adding test (ultra diluted) and reference (5\% commercial tincture) solutions, cell cultures were kept at $37^{\circ} \mathrm{C}$ in incubator with $5 \% \mathrm{CO}_{2}$ and $100 \%$ relative humidity for 48 hours.

Next, $20 \mu \mathrm{L}$ of 2,5-diphenyl-2H-tetrazolium bromide (MTT) $(2.5 \mathrm{mg} / \mathrm{ml})$ solution was added to each well plate and plates were kept at $37^{\circ} \mathrm{C}$ in incubator with $5 \% \mathrm{CO}_{2}$ and $100 \%$ relative humidity for 4 hours. Then, plates were centrifuged (1500 rpm for $10 \mathrm{~min}$ ) and crystals were dissolved by adding $100 \mu \mathrm{l}$ of isopropyl alcohol; after gentle homogenization, absorbance was determined at 570nm by ELISA reader (Biorad 550).

\section{Data analysis}

Results of absorbance were analyzed by software Prism4 and expressed as raw absorbance data and percentage of control of cells cultured in the culture medium. Statistical significance was analyzed by ANOVA test followed by Newman-Keuls test and established at $\mathrm{p}<0.05$.

\section{Results and discussion}

The results obtained by absorbance showed different degrees of satisfactory cytotoxicity, since there was biological activity besides reduction of cell viability induced by all ultra diluted solutions compared to mothertincture and cisplatin used as standard (figure 2).

Analysis showed that mother-tincture and cisplatin - an antineoplastic agent used as standard in this study [18] - exhibited equivalent cytotoxicity (Figure 2).

Comparison of mother-tincture to all other ultra dilutions and homeopathic medicine also showed it to be more toxic. A study by Camargo et al [19] showed that mother-tincture of Euphorbia tirucalli was more cytotoxic than $\mathrm{EtOH}$ and latex because it contains a greater amount of active principles (10\% active principles/inert vehicle).

A study by Aquino [20] using 1\% and 10\% ultra dilutions of latex and EtOH evidenced the damage induced by $\mathrm{EtOH}$ on cell lines. For this reason, we chose to test ultra diluted $\mathrm{EtOH}$ in lower concentration (0.5\% and 5\%) to warrant the integrity of cells. 


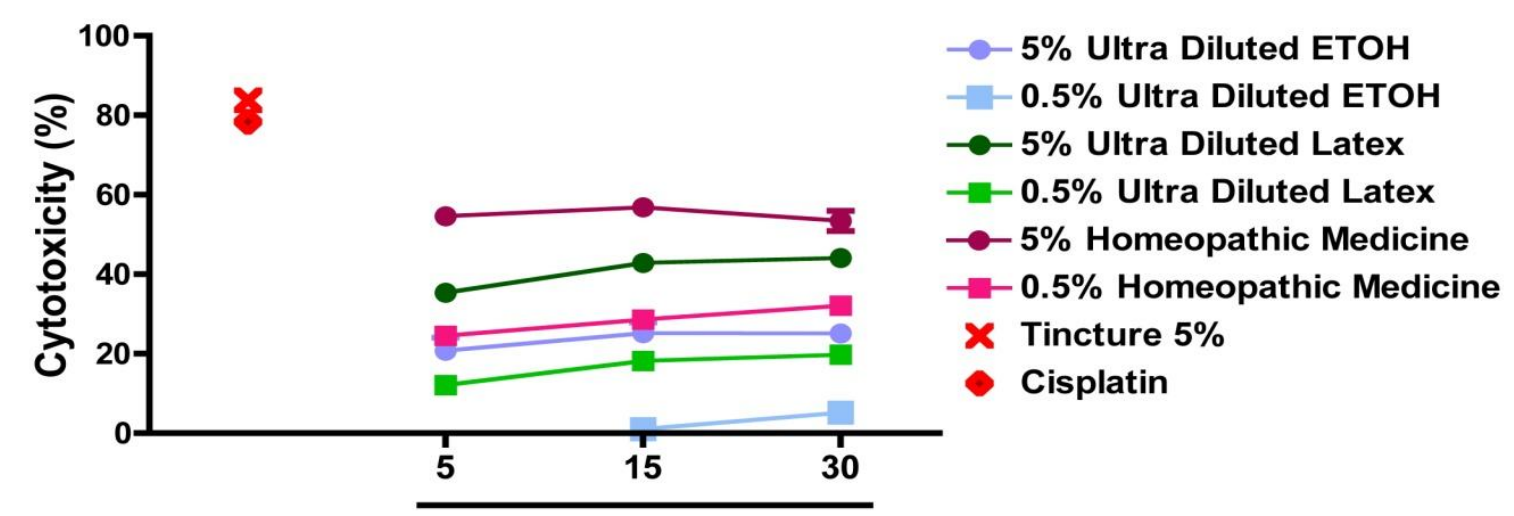

High Dilution $(\mathrm{CH})$

Figure 2: Comparison among mother-tincture (Euphorbia tirucalli L.), cisplatin, ultra diluted EtOH, ultra diluted latex and homeopathic medicine.

Comparison between culture medium and $0.5 \% \mathrm{EtOH}$ resulted in no alterations, thus showing that EtOH used as vehicle had no significant influence on the remainder of tests (figure 3).
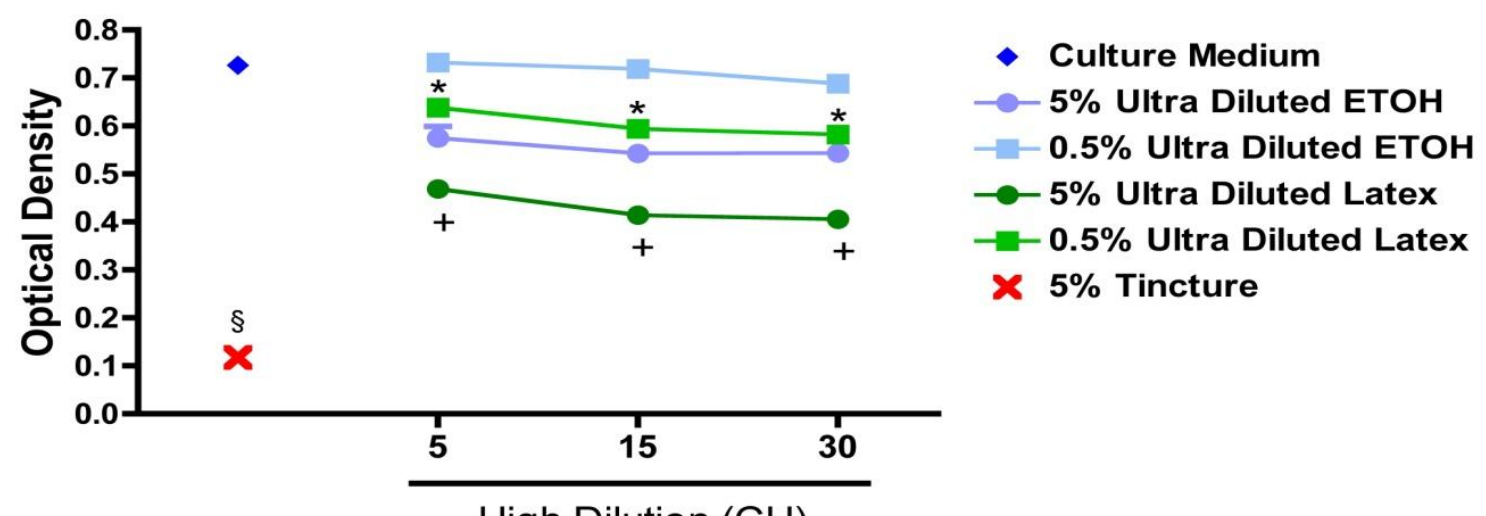

High Dilution $(\mathrm{CH})$

Figure 3: Comparison of ultra diluted latex and $\mathrm{EtOH}$ with culture medium and mother-tincture (Euphorbia tirucalli L.). + means $\mathrm{p}<0.05$ compared to group $5 \% \mathrm{EtOH}$ of the corresponding high dilution. * means $\mathrm{p}<0.05$ when compared to group $0.5 \% \mathrm{EtOH}$ of the corresponding high dilution. $\S$ means $\mathrm{p}<0.05$ compared to group culture medium.

It was observed that mother-tincture exhibited a high index of toxicity. When comparing ultra diluted EtOH and latex, $0.5 \%$ and $5 \%$ ultra diluted latex exhibited a higher index of toxicity. Even with $5 \% \mathrm{EtOH}$, difference of cytotoxicity compared to $0.5 \%$ was very small, thus indicating that $0.5 \%$ and $5 \% \mathrm{EtOH}$ did not interfere with the experiment. 
Varricchio et al [21] were able to show in a toxicological study that ultra diluted latex in dilutions $5 \mathrm{cH}, 15 \mathrm{cH}$ and $30 \mathrm{cH}$ was effective against tumor cells proliferation. In turn Barbosa [22], assessing the toxicological effects of firestick cactus (extract) on tumor cells in in vitro models and in vivo neoplasm using sarcoma 180 in mice concluded that firestick cactus induced $58.9 \%$ in vitro inhibition of sarcoma 180 .

Silva's [23] studies on mutagenesis and cytotoxicity induced by E. tirucalli concluded that it has inhibiting action on the cellular cycle as well as genotoxic action.

Figure 4 shows that homeopathic medicine Euphorbia tirucalli exhibited a considerable index of cytotoxicity.
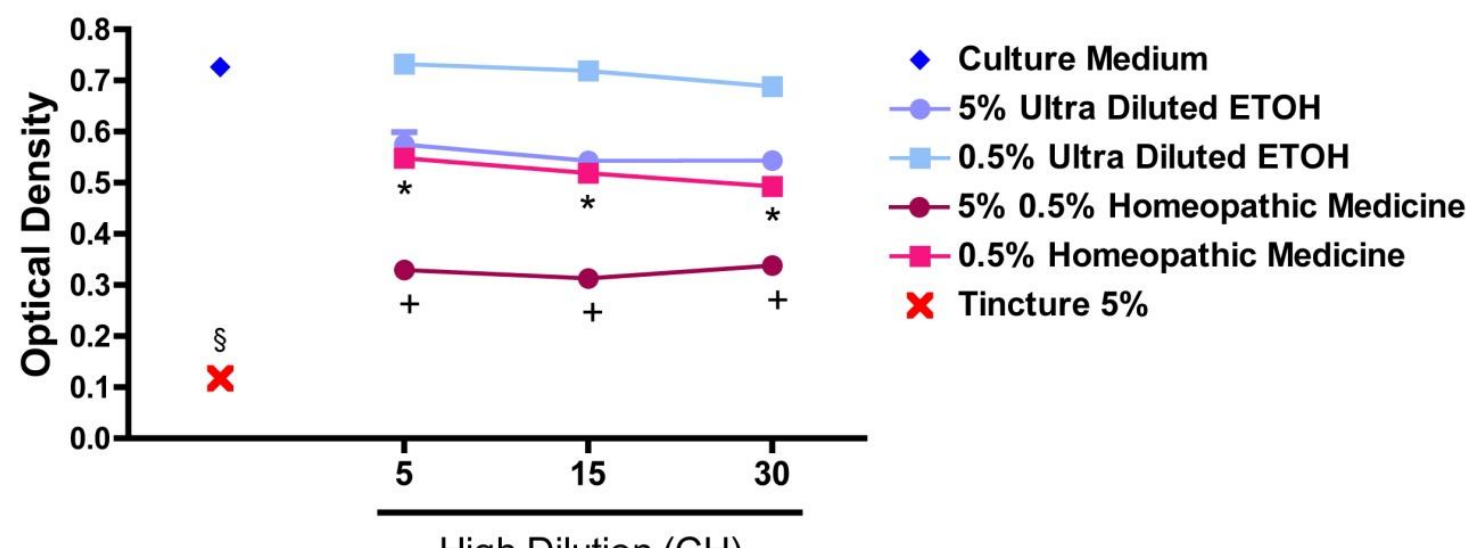

High Dilution $(\mathrm{CH})$

Figure 4: Comparison among the following preparations: ultra diluted EtOH and tincture; mother-tincture (Euphorbia tirucalli L.). + means $\mathrm{p}<0.05$ compared to group 5\% EtOH of the corresponding high dilution. * means $\mathrm{p}<0.05$ when compared to group $0.5 \% \mathrm{EtOH}$ of the corresponding high dilution. $\S$ means $\mathrm{p}<0.05$ compared to group culture medium.

Comparison between mother-tincture and homeopathic medicine showed that the latter even when $0.5 \%$ and $5 \%$ diluted exhibited significant cytotoxic activity.

Figure 4 also shows that homeopathic medicine Euphorbia tirucalli was associated with better inhibition of cell growth activity.

In turn Pessoa [24], also studying Euphorbia tirucalli, found low in vitro cytotoxicity and significant inhibition (60\%) of tumor growth using hydroalcoholic extracts on cells.

\section{Conclusion}

Our results show that both homeopathic medicine Euphorbia tirucalli and ultra diluted latex in dilutions $5 \mathrm{cH}, 15 \mathrm{cH}$ and $30 \mathrm{cH}$ showed good performance inhibiting human melanoma (MV3) proliferation. Further studies should be carried out to establish the therapeutic use of ultra diluted firestick cactus in tumors.

\section{References}

[1] Machado, Michel M. Perfil Fito químico e Avaliação dos Principais Efeitos Biológicos e Imunológicos in vitro da Euphorbia tirucalli L. 105p. Monografia (Pós-Graduação - Mestrado), Ciências Farmacêuticas Universidade Federal de Santa Maria, 2007. 
[2] Oliveira, Ângela P.; Nepomuceno, Júlio César. Avaliação dos Efeitos Genotóxicos e Antigenotóxicos do Avelós (Euphorbia tirucalli) Em Drosophila melanogaster. Bioscience Journal. v.20, n. 2, p. 179-186, 2004.

[3] Martins, Ernane R. et al. Plantas Medicinais. Viçosa: UFV, Editora UFV, 1998.

[4] Varricchio, Márcia Cristina B. N. et al. Euphorbia tirucalli: Análise Qualitativa do Desenvolvimento Vegetal Durante o Cultivo in vitro. BioFar. v. 3, n. 1, p. 53-65, 2008a.

[5] Varricchio, Márcia Cristina B. N. et al. Cultivo in vitro de Euphorbia tirucalli (Aveloz), Avaliação da Constituição Química do Látex em Diferentes Condições de Cultivo, e Teste de Atividade Larvicida e Juvenilizante em Aeds aegypti. BioFar. v. 2, n.1, $2008 \mathrm{~b}$.

[6] Füstenberger, G.; Hecker, E. On The Active Principles Of The Euphorbiaceae, XII. Highly Unsaturated Irritant Diterpene Esters From Euphorbia tirucalli Originating From Madagascar. Journal of Natural Products. v. 49, n. 3, p. 386-397, 1986.

[7] Inca. Instituto Nacional de Câncer. Incidência de Câncer no Brasil, 2010. Disponível em: http://www.inca.gov.br/estimativa/2010. Acessado em: 08 de agosto de 2010.

[8] Caseiro, Bianca Menegazzi et al. Estudo do Potencial de Cura de Formas de Câncer Utilizando Aveloz (Euphorbia tirucalli). MICTI, v.1; p.22, 2006.

[9] Silva, Aldo César P. Abordagem da Atividade Biológica do Látex de Euphorbia tirucalli Linn. (Euphorbiaceae). 116p. Dissertação (Mestrado), Ciências Farmacêuticas - Universidade Federal de Pernambuco, 2006.

[10] Varricchio, Márcia Cristina B. N. et al. Emprego do Avelós (Euphorbia tirucalli) Dinamizado no Tratamento do Câncer. Instituto Hanhemanniano do Brasil. v. 6, n.1, p. 64-67, 2000.

[11] Caxito, Marina L. C. Avaliação da Citotoxicidade e Perfil Cromatográfico de Extratos de Euphorbia tirucalli (Avelóz) de Diferentes Regiões do Brasil. 113p. Dissertação (Mestrado), Biotecnologia Vegetal Universidade Federal do Rio de Janeiro, 2007.

[12] Clarke, John Henry M. D. A Dictionary of Practical Matéria Médica. v. 1. Índia: Jain Publishing CO, 1978.

[13] Vijnovsky, Bernardo. Tratado de Matéria Médica Homeopática. 2. ed. Buenos Aires: Gráfica Editora, 1992.

[14] Boericke, William M. D. Matéria Médica Homeopática com Índice Terapêutico. 2. ed. Rio de Janeiro: Kosmos. 1993.

[15] Teixeira, Marcus Z. Homeopatia: Ciência, filosofia e arte de curar. Rev Med. v. 85, n. 2, p. 30-43, 2006.

[16] Varricchio, Márcia Cristina B. N.; Silva, Simone N.; Varricchio, Marcos Tadeu. "Euphobia tirucalli: redimencionamento clínico e contribuição à graduação e à pós-graduação após pesquisa em biotecnologia vegetal”. BioFar. v. 03, n. 01, p. 71-80, 2009.

[17] ABFH - Associação Brasileira de Farmacêuticos Homeopatas. Formas Farmacêuticas Derivadas. In: Manual de normas técnicas para preparações homeopáticas. Cap. 8, Curitiba: 3 ed., 2003, p.7. 
[18] Gonçalves, Estela Maria. Efeito da cisplatina em cultura de linhagens estabelecidas e sua capacidade de induzir transformação celular in vitro. 120p. Dissertação (Doutorado), Biologia Celular e EstruturalUniversidade Estadual de Campinas, 2005.

[19] Camargo, Mauricio et al. Efectos Sobre el Ciclo Celular de Extractos de Euphorbia aphylla. Actual Biol, v. 20, n. 69 , p. $121-130,1998$

[20] Aquino, Carolina L. et al. High dilutions of Euphorbia tirucalli L. (Aveloz) modify the viability and glycolitic metabolism of cell lines. International Journal of High Dilution Research. v. 7, n. 24, p. 132-139, 2008 .

[21] Varricchio, Márcia Cristina B. N. et al. O uso de Euphorbia tirucalli (Aveloz) em medicina tradicional e as evidências científicas. BioFar. v. 03, n. 01, p. 84- 92, 2008c.

[22] Barbosa, Círia V. Avaliação do Potencial Antineoplásico de Plantas Medicinais Utilizadas Como Coadjuvantes no Tratamento do Câncer Pelos Pacientes do CACON / UFAL. 112p. Dissertação (Mestrado), Ciências da Saúde - Universidade Federal de Alagoas, 2009.

[23] Silva, Liz Carmem. Mutagênese e Citotoxicidade do Látex da Euphorbia tirucalli Linn. (aveloz) (Euphorbiaceae). 99p. Dissertação (Mestrado), Genética e Biologia Molecular - Universidade Federal do Rio Grande do Norte, 1999.

[24] Pessoa, Cláudia O. Testes in vivo e in vitro Para Avaliação de Citotoxicidade e Atividade Antitumoral de Plantas no Nordeste Brasileiro. 126p. Dissertação (Mestrado), Farmacologia - Universidade Federal do Ceará, 1992.

\title{
Análise da atividade in vitro de altas diluições de Euphorbia tirucalli $L$. em cultura de células de melanoma humano
}

\begin{abstract}
RESUMO
Aveloz (Euphorbia tirucalli L.) é uma planta da família Euphorbiaceae, caracterizada pela produção de um látex tóxico, que quando em contato com mucosas e pele tem ação corrosiva. O uso tópico e contínuo deste látex vem sendo indicado na medicina popular para tratamento de verrugas, e epiteliomas. Para validar o uso popular da Aveloz, o látex ultradiluído e o medicamento homeopático Euphorbia tirucalli L. foram testados in vitro sobre a proliferação de células de melanoma. O látex ultradiluído foi obtido através do processo de diluiçaõ e agitação (método de trituração para fase sólida e sucussão para fase líquida), usando EtOH $70^{\circ} \mathrm{GL}($ Álcool etílico de alcoolatura de $70^{\circ}$ Gay Lussac) como insumo inerte nas diluições homeopáticas de $5 \mathrm{cH}, 15 \mathrm{cH}$ e 30cH, conforme preconizado pela Farmacopeia Homeopática Brasileira(FHB). O medicamento homeopático Euphorbia tirucalli foi obtida a partir da tintura-mãe e preparado pelo método hahnemanniano na escala centesimal. Soluções de EtOH $70^{\circ}$ GL (0,5 e 5\%) foram sucussionadas e usadas como controle neste experimento. Células de melanoma humano foram cultivadas, tratadas e monitoradas pelo método MTT no intervalo de tempo de $24 \mathrm{~h}$ a $72 \mathrm{~h}$. Observou-se que a solução de EtOH 0,5\% teve pouco ou nenhum efeito sobre
\end{abstract}


a proliferação de células de melanoma (inibição máxima de 5,1\% no grupo 30cH ). Na maioria dos grupos, observou-se uma correlação positiva entre o grau de inibição da proliferação e a diluição dos preparativos, máximo de aumento de $9 \%$ no grupo do látex $5 \%$. Além disso, a tintura mãe foi mais ativa do que o látex , no tratamento com $0,5 \%$ de látex $30 \mathrm{cH}$ mostrou uma inibição de $19,7 \%$, enquanto no tratamento com $0,5 \%$ do medicamento homeopático Euphorbia tirucalli 30cH houve uma inibição de $32,1 \%$ da proliferação celular $(\mathrm{p}<0.05)$. Estes resultados sugerem um possível uso terapêutico do Aveloz em ultra-diluições (principalmente na potência 30cH) sobre melanoma, sendo necessários novos ensaios para aprofundamento deste estudo.

Palavras-chave: Euphorbia tirucalli, ultra-diluições, atividades antitumorais.

\section{Introdução}

O Aveloz é uma planta da família Euphorbiaceae e de nome científico Euphorbia tirucalli L. Este gênero é caracterizado pela produção de um látex tóxico, que quando em contato com mucosas e pele tem ação corrosiva [1]. É uma planta nativa da África e que chegou ao Brasil em 1892 e é conhecida popularmente também como árvore-do-coral-de-são-sebastião [2], cega-olho, coral-verde, dente-de-cão, dedo-do-diabo, graveto-de-diabo, labirinto, coroa-de-cristo, almeidinha e mata-verrugas. Como características gerais desta planta, pode-se dizer que é um arbusto lactescente, pubescente e sublenhosa, de ramos cilíndricos, verticilados, filiformes de coloração verde, (figura 1); as flores femininas são terminais e axilares, com coloração amarelada ou esverdeada, enquanto as masculinas ficam ao redor da feminina [3].

Figura 1: Euphorbia tirucalli L., A. aveloz, partes aéreas; B. detalhe do látex exsudando

A composição fitoquímica do caule do aveloz constitui-se de antocianinas (taninos condensados), flavonóides, e traços de alcalóide e esteróides, enquanto que no látex encontram-se triterpenóides e diterpenóides [4;5]. Os triterpenos eufol, tirucalol, taraxasterol, diversos ácidos orgânicos, hidrocarbonetos e um derivado isoquinolínico foram isolados na E. tirucalli africana, sendo na sua maioria biologicamente inerte, os álcoois parentais ingenol e o forbol não são promotores tumorais, diferentes dos ésteres diterpênicos de forbol que são [5;6]. O uso interno do látex desta planta apresenta indicações para carcinomas e epiteliomas benignos; também atua contra picada de escorpião e cobras e é purgativo. Seu uso externo tem indicações antirreumáticas, rubefascientes e para a extração de verrugas [5;6].

Embora esta planta também tenha sido comumente utilizada na construção de cercas vivas, vale lembrar que o uso do aveloz para tal finalidade não é recomendado pelo fato de seu látex causar toxicidade [5;6].

Segundo estimativa do Instituto Nacional de Câncer - INCA em prevalência de câncer no Brasil, as neoplasias malignas representam a segunda causa de morte na população desde 2003; dados estes notificados em 2007 pelo sistema de informação sobre mortalidade [7]. Vale lembrar que a alta prevalência de câncer na população levou a um grande impulso no desenvolvimento de pesquisas em câncer, dentre elas, o estudo de uma antiga crença popular que visa a cura do câncer por meio dessa espécie [8].

Em seus estudos, Silva [9] avaliou a toxicidade aguda da aveloz e verificou sua função antiinflamatória/analgésica e antitumoral. Na medicina popular e na prática homeopática, o aveloz vem sendo utilizado como terapêutica complementar para o tratamento do câncer. Embora comumente utilizada na medicina popular, Caxito [10] salienta que a constituição química da E. tirucalli L. sofre alterações quando submetida a condições ambientais distintas. Sua pesquisa revelou que o uso da planta em questão deve levar em conta as variações geográficas e sazonais para que se possa determinar sua verdadeira citotoxicidade. 
No que se refere à homeopatia, pode-se verificar através da descrição das matérias médicas que o aveloz, em doses alopáticas, é capaz de causar toxicidade. Entretanto, em doses dinamizadas, como é preparado o medicamento homeopático, pode ser empregado em diversos tipos de tratamento e indicações clínicas como dores terebrantes e semelhantes aos quadros de neoplasias [ 11;12;13 ].

Doses homeopáticas têm caráter essencialmente qualitativo e não quantitativo; diferente de doses alopáticas que significam a quantidade de medicamentos administrados por vez ou por dia ao paciente, capaz de modificar seu estado [14].

Varricchio et al [15;16] apontam para uma atividade antitumoral do aveloz, analisada em testes "in vitro" e "in vivo" a partir de preparações homeopáticas ultradiluídas nas potências $5 \mathrm{cH}, 15 \mathrm{cH}$ e $30 \mathrm{cH}$.

\section{Materiais e Métodos}

O látex da Euphorbia tirucalli L. foi coletado de um exemplar cultivado nos jardins da Fundação Oswaldo Cruz do Rio de Janeiro. A coleta foi realizada no final da tarde a partir de amostras de talos extraídos diretamente da planta. $0,1 \mathrm{~g}$ do látex coletado foi mantido sob refrigeração durante $24 \mathrm{~h}$ e posteriormente, triturado com lactose até $3 \mathrm{cH}$ em gral de porcelana, segundo a técnica recomendada pela Farmacopeia Homeopática Brasileira. Sequencialmente, a $3 \mathrm{cH}$ foi solubilizada em EtOH $20^{\circ} \mathrm{GL}$ e sucussionada para a obtenção da $4 \mathrm{cH}$. A $5 \mathrm{cH}$ foi posteriormente preparada pela mistura de 1 parte da $4 \mathrm{cH}$ diluída em 99 partes de EtOH $70^{\circ} \mathrm{GL}$. Este procedimento de diluição de 1:100 e de sucussão mecânica (Denise 10-50, AUTIC) foi repetido até a obtenção da $30 \mathrm{cH}$, sempre usando a potência anterior como preparação para a subsequente. Foram obtidos a partir deste método o medicamento homeopático Euphorbia tirucalli, látex dinamizado e EtOH dinamizado.

\section{Teste de atividade sobre o crescimento celular}

Células de melanoma humano MV3 (linhagem cedida pela Profa Dra Thereza Christina Barja-Fidalgo; IBRAG, UERJ) foram cultivadas em meio de cultura DMEM suplementado com 10\% de soro bovino fetal e antibióticos (Estreptomicina e Penicilina). Foram semeadas ( $5 \times 10^{3}$ células/poço) em placas de 96 poços em um volume de $100 \mu \mathrm{L}$. Após a semeadura das células, as placas foram mantidas em incubadora a $37^{\circ} \mathrm{C}, 5 \%$ de $\mathrm{CO}_{2}$ e $100 \%$ de umidade relativa, por $24 \mathrm{~h}$.

Decorridas as $24 \mathrm{~h}$, as soluções dinamizadas foram diluídas a 0,5 e 5\%. Foram realizadas diluições seriadas (2 vezes) num total de 2 diluições de cada composto, o mesmo é feito para o veículo dinamizado (EtOH 70\%). Foram adicionados $100 \mu \mathrm{L}$ das soluções teste aos poços já contendo $100 \mu \mathrm{L}$ de meio, diluindo assim os compostos para a diluição final desejada de 0,5 e $5 \%$ em triplicata.

Após a adição das soluções teste (dinamizadas) e da solução referência (tintura comercial diluída 5\%), as culturas celulares foram mantidas em incubadora a $37^{\circ} \mathrm{C}, 5 \%$ de $\mathrm{CO}_{2}$ e $100 \%$ de umidade relativa, por $48 \mathrm{~h}$.

Decorrido este período, foi adicionado a cada poço $20 \mu \mathrm{L}$ da solução de 2,5-difenil-2-H-brometo de tetrazolium (MTT), $(2,5 \mathrm{mg} / \mathrm{mL})$ que é um sal de tetrazólium e as placas foram incubadas por 4 horas em incubadora a $37^{\circ} \mathrm{C}, 5 \%$ de $\mathrm{CO}_{2}$ e $100 \%$ de umidade relativa. Após o período de incubação, a placa foi centrifugada (1500rpm por $10 \mathrm{~min}$ ), e os cristais solubilizados pela adição de $100 \mu \mathrm{L}$ de álcool isopropílico e, após uma homogeneização gentil, a absorbância foi determinada a $570 \mathrm{~nm}$ em leitor de ELISA (Biorad 550)

\section{Análise dos Dados}


Os resultados de absorbância obtidos foram analisados utilizando o programa Prism4 e expressos como valores brutos de absorbância e percentagem do controle de células cultivadas em meio de cultura. A significância estatística foi analisada pelo teste ANOVA seguido do teste Newman-Keuls e considerada para valores de $\mathrm{p}<0.05$.

\section{Resultados e discussão}

Os resultados obtidos por absorbância mostraram diferentes graus de citotoxicidade, satisfatórios, já que houve atividade biológica, além de uma diminuição da viabilidade celular induzida por todas as soluções dinamizadas, comparadas com a tintura-mãe e cisplatina como padrão (figura 2).

Figura 2: Comparação da tintura mãe (Euphorbia tirucalli) com cisplatina, EtOH dinamizado, látex dinamizado e medicamento homeopático.

Analisando a tintura mãe e a cisplatina, um agente antineoplásico, utilizado como padrão neste estudo [19], observamos que a tintura mãe e a cisplatina apresentaram citotoxicidade equivalente (Figura 2).

Ao comparar a tintura mãe com os demais dinamizados e medicamento homeopático, observou-se também uma maior citotoxicidade sobre os demais. Em estudo realizado por Camargo et al [20] observaram que a tintura mãe da Euphorbia tirucalli também foi mais citotóxica comparada ao EtOH e ao látex, porque ela contém a maior quantidade de insumo ativo, já que encontra-se na concentração de $10 \%$ de insumo ativo e insumo inerte.

Estudos realizados por Aquino [21], usando 1 e 10\% de diluição do látex e EtOH dinamizados, mostraram danos provocados pelo EtOH em suas linhagens celulares. Mediante a esta toxicidade comprovada pelo EtOH dinamizado e diluído a $10 \%$, considerou-se relevante analisá-lo em concentrações menores (0,5\% e 5\%) para garantir a integridade celular.

Comparando o meio de cultura com EtOH 0,5\%, observou-se que não houve alteração, demonstrando que o EtOH usado como veículo não teve influência significativa na análise dos demais testes (figura 3).

Figura 3: Comparação do látex e EtOH dinamizados com meio de cultura e tintura mãe (Euphorbia tirucalli). + Significa $\mathrm{p}<0.05$ quando comparado ao grupo EtOH $5 \%$ da dinamização correspondente. * Significa $\mathrm{p}<0.05$ quando comparado ao grupo $\mathrm{EtOH} 0.5 \%$ da dinamização correspondente. $\S$ Significa $\mathrm{p}<0.05$ quando comparado ao grupo Meio.

Observou-se que a tintura mãe apresentou um alto índice de citotoxicidade. Ao comparar EtOH e látex dinamizados, observou-se que o látex dinamizado e diluído 0,5\% e 5\% apresentaram um maior índice de citotoxicidade. Mesmo o EtOH a $5 \%$ a diferença de citotoxicidade comparada ao látex 0,5\% é muito pequena, mostrando que o EtOH 0,5\% e 5\% não interferem no experimento.

Varricchio et al [22] puderam comprovar em estudo toxicológico do látex ultradiluído que o látex dinamizado nas potências $5 \mathrm{cH}, 15 \mathrm{cH}$ e $30 \mathrm{cH}$ apresentaram eficácia frente às células tumorais. Barbosa [23] por sua vez avaliando os efeitos toxicológicos do aveloz (extrato) sobre células tumorais em modelos in vitro e em neoplasias in vivo, utilizando-se sarcoma $180 \mathrm{em}$ camundongos, concluiu que testes in vitro do aveloz inibiu o sarcoma 180 em $58,9 \%$.

Silva [24] em seus estudos sobre mutagênese e citotoxicidade induzida pela Euphorbia tirucalli L. (aveloz), concluiu que o aveloz possui atividade inibitória do ciclo celular, bem como ação genotóxica. 
Na figura 4 pôde-se observar que o medicamento homeopático Euphorbia tirucalli apresentou um considerável índice de citotoxicidade.

Figura 4: Comparação entre os seguintes elementos: EtOH e tintura dinamizados; tintura mãe (Euphorbia tirucalli). + Significa p $<0.05$ quando comparado ao grupo EtOH $5 \%$ da dinamização correspondente. * Significa $\mathrm{p}<0.05$ quando comparado ao grupo EtOH $0.5 \%$ da dinamização correspondente. § Significa $\mathrm{p}<0.05$ quando comparado ao grupo Meio.

Ao comparar-se a tintura mãe com o medicamento homeopático, observou-se que este, mesmo diluído 0,5\% e $5 \%$, apresentou uma atividade citotóxica significativa.

A partir da análise da figura 4, vale ressaltar também que na potência $15 \mathrm{cH}$, o medicamento homeopático apresentou uma melhor atividade de inibição de crescimento celular.

Pessoa [25] por sua vez, em estudos realizados com Euphorbia tirucalli, teve como resultados uma baixa citotoxicidade in vitro e uma significante inibição do crescimento tumoral de $60 \%$ em extratos hidroalcoólicos testados em células.

\section{Conclusão}

A partir dos resultados apresentados, pôde-se verificar que tanto o medicamento homeopático Euphorbia tirucalli como também o látex dinamizado nas potências $5 \mathrm{CH}, 15 \mathrm{CH}$ e $30 \mathrm{CH}$ apresentaram bom desempenho inibindo a proliferação de células de melanomas humanos (MV3).

Estudos devem ser realizados para estabelecer o uso do aveloz ultadiluido na terapêutica antitumoral .

\section{(c)) EY-NC-ND Licensed to GIRI}

Support: authors declare that this study received no funding

Conflict of interest: authors declare there is no conflict of interest

Correspondence author: Tereza Cristina de A.Leitão, terezaleitao@oi.com.br

How to cite this article: Silva R.M.R.J; Teixeira,D.F.; Sampaio, A.L.F.\& Leitão, T.C.A. A.Analysis of in vitro activity of high dilutions of Euphorbia tirucalli L. in human melanoma cells. Int J High Dilution Res [online]. 2011 [cited YYYY Month dd]; 10(36): 183-193. Proceedings of the XXV GIRI Symposium and VIII CBFH; 2011 Sep 04-07; Foz do Iguaçu (Brazil). GIRI and ABFH; 2011; Available from: http://www.feg.unesp.br/ ojs/index.php/ijhdr/article/view/504/516 